\title{
KESIAPAN INFRASTRUKTUR PUSKESMAS TAMPAKSIRING I KABUPATEN GIANYAR BALI DALAM MENGIMPLEMENTASIKAN PROGRAM JKN
}

\author{
Riskadewi Agatha ${ }^{1}$, Indraguna Pinatih ${ }^{1}$ \\ Fakultas Kedokteran Universitas Udayana, Denpasar, Bal ${ }^{1}$ \\ (riskadewiagatha20@gmail.com)
}

\section{ABSTRAK}

Latar belakang: Program JKN, menuntut pusat kesehatan masyarakat sebagai lini pertama untuk menyediakan fasilitas yang memadai. Kesiapan infrastruktur pusat kesehatan masyarakat Tampak Siring I menjadi salah satu point yang perlu diperhatikan untuk menilai kesiapan puskesmas dalam menghadapi era JKN.

Tujuan: Tujuan penelitian ini adalah Untuk mengetahui kesiapan infrastruktur Puskesmas Tampaksiring I dalam mengimplementasikan sistem JKN.

Metode: Peneilitian ini adalah penelitian deskriptif kualitatif. Penelitian ini dilakukan untuk meneliti kesiapan infrastruktur Puskesmas Tampaksiring I dalam mengimplementasikan program JKN. Hal tersebut dilihat berdasarkan observasi langsung terhadap infrastruktur dan wawancara secara mendalam

Hasil: Gedung Puskesmas Tampaksiring I masih belum memenuhi standart karena walaupun bangunan gedung telah permanen dan memenuhi standard keamanan dan kemudahan dalam pemberian pelayanan serta perlindungan dan keselamatan bagi semua orang termasuk penyandang cacat, anak-anak, dan orang lanjut usia. Bangunan klinik belum memperhatikan fungsi gedung dan kenyamanan. Hal ini dibuktikan dengan masih adanya pemanfaatan ruangan yang tidak semestinya. Salah satu contoh yang sering terjadi adalah, kegiatan imunisasi sering dilakukan di ruang istirahat pegawai sedangkan puskesmas tersebut sudah memiliki ruang tersendiri untuk kegiatan imunisasi. Selain itu pada ruang imunisasi pencahayaannya kurang maksimal. Dari sisi non gedung puskesmas memiliki 2 buah mobil ambulans, 1 buah mobil puskesmas keliling, tempat sampah medis/nonmedis, peralatan medis gawat darurat, bahan habis pakai, dan alat sterilisasi namun terdapat kekurangan pada ketersediaan obat-obatan gawat darurat dan obat standard untuk menangani 144 penyakit yang harus tuntas pada tingkat PPK1. Selain itu masih terdapat kendala pada ketersediaan alat-alat laboratorium. Dari penelitian ini, dapat disimpulkan bahwa faktor infrastruktur yang menonjol dalam pelaksanaan JKN di Puskesmas Tampaksiring I sarana gedung dan nongedung yang masih belum memadahi.

Kata Kunci: Kesiapan Infrastruktur, JKN

\section{ABSTRACT}

Background: Program JKN, demanding public health centers as first-line to provide adequate facilities. Community health center infrastructure readiness Siring I became one of the points that need to be considered to assess the readiness of health centers in the era of JKN.

Purpose: The purpose of this study was to determine the readiness of Sukawati I PHC infrastructure in implementing JKN system.

Methods: This was a descriptive research studies on qualitative. This study was conducted to examine the PHC infrastructure readiness in implementing the Sukawati I JKN. It is seen by direct observation of the infrastructure and in-depth interviews

Results: Building Health Center Sukawati I still do not meet the standard because although the building has a permanent and meet safety standards and ease of service delivery and the protection and safety of all persons, including persons with disabilities, children, and the elderly. Building clinics have not noticed the building function and comfort. This is evidenced by the presence of an improper use of the room. One common example is, immunization activities are often carried out in the employee break room while the health center already has 
a separate room for immunization activities. In addition to the immunization room lighting is less than the maximum. From the non-building health center has 2 ambulances, 1 car mobile health clinics, a medical waste / non-medical, emergency medical equipment, consumables, and sterilizer, but there is a shortage in the availability of emergency medicine and drug standards to handle 144 diseases that must be completed in PPK1 level. In addition there are constraints on the availability of laboratory equipment. From this study, it can be concluded that a prominent factor in the implementation of infrastructure in health centers JKN Sukawati I nongedung facilities and buildings that are still not memadahi.

\section{Keywords: Infrastructure Readiness, JKN}

\section{PENDAHULUAN}

Hak tingkat hidup yang memadai untuk kesehatan dan kesejahteraan diri merupakan hak asasi manusia dan diakui oleh segenap bangsa-bangsa di dunia, termasuk Indonesia. Pengakuan itu tercantum dalam Deklarasi Perserikatan Bangsa-Bangsa tahun 1948 tentang Hak Azasi Manusia. Hak ini juga tercantum dalam UUD 45 pasal $28 \mathrm{H}$ dan pasal 34, dan diatur dalam UU No. 23/1992 yang kemudian diperkuat dengan UU 36/2009 tentang Kesehatan. Berdasarkan deklarasi dan konstitusi tersebut, pemerintah bertanggung jawab atas pelaksanaan jaminan kesehatan masyarakat melalui Jaminan Kesehatan Nasional (JKN) bagi kesehatan perorangan. ${ }^{1,2}$

Melihat dari perjalanan sistem jaminan kesehatan di Indonesia, penduduk Indonesia 151,5 juta jiwa (63,5\%) telah mempunyai jaminan kesehatan dengan berbagai cara penjaminan. Itu termasuk para peserta Jamkesmas, Jamkesda, Askes, PNS Pensiunan dan Veteran, TNI POLRI aktif, Jamsostek, jaminan oleh perusahaan dan individu peserta jaminan kesehatan dari perusahaan asuransi kesehatan swasta. ${ }^{3}$ Artinya, masih terdapat 37 persen penduduk atau 87 juta jiwa yang belum tercakup dalam jaminan kesehatan. Pada saat itu berbagai macam cara penjaminan ini masih terfragmentasi dan tidak mencakup seluruh penduduk. Biaya kesehatan dan mutu pelayanan menjadi sulit terkendali. Untuk mengatasi hal itu, pada 2004, dikeluarkan Undang-Undang No.40 tentang Sistem Jaminan Sosial Nasional (SJSN). UU 40/2004 ini mengamanatkan bahwa jaminan sosial wajib bagi seluruh penduduk termasuk Jaminan Kesehatan Nasional (JKN) melalui suatu Badan Penyelenggara Jaminan Sosial (BPJS). ${ }^{3,4}$

WHO merumuskan tiga dimensi dalam pencapaian universal coverage yaitu (1) seberapa besar persentase penduduk yang dijamin; (2) seberapa lengkap pelayanan yang dijamin, serta (3) seberapa besar proporsi biaya langsung yang masih ditanggung oleh penduduk. Dimensi pertama adalah jumlah penduduk yang dijamin. Dimensi kedua adalah layanan kesehatan yang dijamin, misalnya apakah hanya layanan di rumah sakit atau termasuk juga layanan rawat jalan. Dimensi ketiga adalah proporsi biaya kesehatan yang dijamin. Dapat saja seluruh penduduk dijamin biaya perawatan di rumah sakit, tetapi setiap penduduk harus bayar sebagian biaya di rumah sakit. Perluasan jaminan ketiga dimensi sangat tergantung pada kemampuan keuangan suatu negara dan pilihan penduduknya. ${ }^{4}$

Untuk menjamin bahwa layanan dokter dan rumah sakit berkualitas, BPJS juga akan mengembangkan seleksi (kredensialing) dokter dan fasilitas kesehatan yang dikontrak. Fasilitas yang tidak memenuhi standar tidak akan dikontrak atau diperpanjang kontraknya. Diharapkan pada tahun 2019 seluruh fasilitas kesehatan akan memenuhi standar yang berlaku agar kepuasan peserta terpenuhi. Karena peserta diberikan kebebasan memilih dokter/fasilitas kesehatan yang akan melayaninya, maka seluruh fasilitas kesehatan akan bersaing memberikan layanan yang berkualitas dan memuaskan. Dengan mengembangkan sistem dan pemantauan kepuasan peserta, pada tahun 2019 diharapkan $85 \%$ peserta puas terhadap layanan kesehatan berkualitas. ${ }^{9,10}$

Dengan tanggung jawab yang demikian besar tersebut, maka Puskesmas sebagai fasilitas kesehatan primer di masing-masing daerah di Indonesia diharapkan siap untuk mampu menggunakan sumber daya yang telah diberikan oleh pemerintah sebaik-baiknya dengan tidak mengesampingkan aspek pelayanan kesehatan kepada masyarakat. Untuk mengimplementasikan hal tersebut, maka diperlukan kesiapan dari infrastruktur puskesmas serta segala pihak khususnya pihak-pihak yang bertugas di Puskesmas agar nantinya dapat terwujud JKN yang efektif dan efisien.

Puskemas Tampaksiring I merupakan salah satu Puskemas yang terdapat di Kecamatan Tampaksiring. Luas wilayah kerja Puskesmas Tampaksiring I sebesar $27,08 \mathrm{~km}^{2}$ dan mewilayahi 3 desa yaitu, Desa Manukaya, Desa Tampaksiring dan Desa Sanding. Jumlah penduduk pada tahun 2013 adalah 22844 jiwa yang terdiri dari 11734 laki-laki dan 11110 perempuan, terdiri dari 6494 KK. Sedangkan jumlah penduduk miskin sesuai hasil 
pendataan tahun 2012 adalah 1980 jiwa. Kunjungan penderita rawat jalan di wilayah kerja Puskesmas Tampaksiring I tahun 2013 adalah 17.804. Data kunjungan menunjukkan sebanyak 3472 kasus menggunakan Jamkesmas, 10769 menggunakan JKBM, sisanya menggunakan Askes dan pasien umum. Pada bulan Januari 2014 didapatkan jumlah kunjungan pengguna JKN sebanyak 414, dan pada bulan Februari 2014 didapatkan jumlah kunjungan pengguna JKN sebanyak $536 .^{7,8}$

Dilihat dari sistem JKN, yang mengharuskan pasien untuk berobat di Klinik Pratama (PPK 1) sebelum ke tingkat yang lebih tinggi, hal ini merupakan sebuah peluang bagi Puskesmas. Di lain pihak, Puskesmas tidak hanya mengedepankan kegiatan promotif dan preventif, namun harus menyeimbangkan aspek kuratif dan rehabilitatifnya. Banyaknya tuntutan terhadap Puskesmas di era JKN ini, membuat hal ini menjadi menarik untuk diteliti untuk menilai bagaimana kesiapan Puskesmas Tampaksiring I dalam mengimplementasikan sistem JKN.

Faktor infrastruktur merupakan aspek yang penting untuk dinilai kesiapannya dalam menghadapi era JKN. Seperti yang telah diketahui, sebagai penyedia layanan kesehatan tingkat satu, Puskesmas memiliki alat-alat yang kurang memadai. Sebagai faktor penunjang, faktor infrastruktur penting untuk diteliti dan dievaluasi lebih lanjut. 6,7

\begin{tabular}{|c|c|c|}
\hline No. & Tugas & Ket \\
\hline 1. & $\begin{array}{l}\text { Memimpin, } \\
\text { mengkoordinasikan dan } \\
\text { mengendalikan kegiatan puskesmas } \\
\text { dalam pelaksanaan pelayanan } \\
\text { kesehatan secara paripurna kepada } \\
\text { masyarakat di wilayah kerja } \\
\text { Puskesmas }\end{array}$ & R1 \\
\hline 2. & $\begin{array}{l}\text { Kontak pertama pasien dalam } \\
\text { pelayanan kesehatan formal sekaligus } \\
\text { penapis rujukan sesuai standar } \\
\text { pelayanan medik }\end{array}$ & R2 \\
\hline 3. & 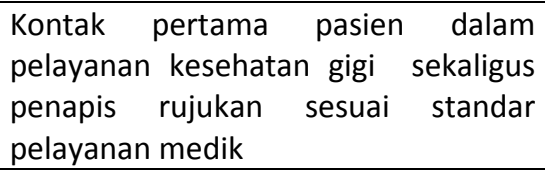 & R3 \\
\hline 4. & $\begin{array}{l}\text { Petugas kesehatan yang berperan } \\
\text { penting dalam membantu dokter guna } \\
\text { memberikan pelayanan kepada } \\
\text { masyarakat di era JKN }\end{array}$ & R4 \\
\hline
\end{tabular}

Belum banyak penelitian baik dalam skala kecil maupun skala besar yang dilakukan untuk menilai bagaimana kesiapan Puskesmas dalam mengimplementasikan sistem JKN. Oleh karena itu, peneliti ingin melakukan suatu penelitian pada Puskesmas Tampaksiring I untuk mengetahui kesiapan Puskesmas dalam mengimplementasikan sistem JKN. Indikator yang dapat dipakai untuk menilai adalah melalui observasi dan mengetahui persepsi petugas Puskesmas, terkait infrastruktur Puskesmas dalam pelaksanaan JKN.

\section{BAHAN DAN METODE}

Peneilitian ini adalah penelitian deskriptif kualitatif. Penelitian dilakukan oleh peneliti ditujukan untuk mengetahui kesiapan infrastruktur puskesmas Tampaksiring I dalam mengimplementasikan JKN. Kesiapaan infrastruktur dilihat dari segi gedung dan nongedung. Penelitian ini dilaksanakan di Puskesmas Tampaksiring I, Kecamatan Tampaksiring, Kabupaten Gianyar. Pengumpulan data dilakukan pada bulan MaretApril 2014.

Penelitian dilihat berdasarkan observasi terhadap infrastruktur dan wawancara secara mendalam terhadap tenaga kesehatan. Untuk mendapatkan data persepsi kesiapan puskesmas tersebut, telah dipilih 4 orang informan yang memiliki kompetensi dan sesuai dengan kebutuhan data sebagai subjek penelitian. Sedangkan untuk observasi, dilakukan menggunakan checklist yang diadaptasi dari Standar Klinik Pratama PKFI tahun 2013. ${ }^{2}$

Validitas data dalam penelitian ini dilakukan cara trianggulasi data atau sumber dan trianggulasi metode. Trianggulasi sumber dilakukan dengan cara membandingkan hasil wawancara antara informan yang satu dengan informan yang lain. Kemudian trianggulasi metode dilakukan dengan cara membandingkan data yang didapatkan dari hasil observasi langsung dengan wawancara.

Analisa data yang digunakan dalam penelitian ini adalah model analisis interaktif (Interactive Model of Analysis) yang memiliki tiga komponen yaitu reduksi data, penyajian data dan penarikan kesimpulan serta verifikasinya.

\section{HASIL DAN PEMBAHASAN}

Penelitian ini menggunakan empat orang petugas Puskesmas Tampaksiring I sebagai informan karena dianggap menguasai permasalahan yang sedang diteliti. Informasi dari lima informan tersebut dianggap sudah dapat mewakili aspek yang berkaitan dengan masalah dalam penelitian.

Tabel 1. Karakteristik Informan Penelitian 
Puskesmas Tampaksiring I merupakan salah satu puskesmas yang berada di bawah Dinas Kesehatan Kabupaten Gianyar. Gedung Puskesmas Tampaksiring I masih belum memenuhi standart karena walaupun bangunan gedung telah permanen dan memenuhi standard keamanan dan kemudahan dalam pemberian pelayanan serta perlindungan dan keselamatan bagi semua orang termasuk penyandang cacat, anak-anak, dan orang lanjut usia. (Standar Klinik Pratama PKFI tahun 2013) Bangunan klinik belum memperhatikan fungsi gedung dan kenyamanan. Hal ini dibuktikan dengan masih adanya pemanfaatan ruangan yang tidak semestinya. Salah satu contoh yang sering terjadi adalah, kegiatan imunisasi sering dilakukan di ruang istirahat pegawai sedangkan puskesmas tersebut sudah memiliki ruang tersendiri untuk kegiatan imunisasi. Selain itu pada ruang imunisasi pencahayaannya kurang maksimal. Penemuan tersebut dikonfirmasi dengan informan sebagai berikut,

"memang betul kegiatan imunisasi sering dilakukan di ruang istirahat pegawai. Hal ini dikarenakan ruang imunisasi yang dimiliki sempit dan gelap." (R1,R4)

Observasi juga dilakukan terhadap empat puskesmas pembantu yang terdapat di wilayah kerja puskesmas Tampaksiring I. Berdasarkan hasil observasi ditemukan bahwa keadaan gedung keempat puskesmas pembantu tersebut jauh dari kata siap. Hal ini dikarenakan gedung puskesmas pembantu tidak memenuhi syarat yang diberikan yakni Konstruksi bangunan harus kuat, terpelihara, bersih yang dapat mencegah penularan penyakit serta kecelakaan (lantai, dinding, pencahayaan ventilasi dan atap, pencegahan dan penanggulangan kebakaran). ${ }^{7,6}$ Sedangkan pada gedung puskesmas pembantu namapak tidak terawat dengan baik terbukti dengan pagar yang mulai rusak, cat tembok yang mulai memudar dan rimbunnya rumput yang tumbuh di sekitar gedung. Gedung puskesmas pembantu juga nampak tidak terurus karena jarang dibuka. Hal tersebut dikonfirmasi dengan informan yang dapat disimpulkan sebagai berikut,

"Seharusnya gedung puskesmas pembantu buaka setiap hari namun hanya dua kali seminggu dikunjungi oleh dokter, namun karena keterbatasan tenaga medis puskesmas pembatu jadi sering tutup. Gedungnya juga kurang sedikit perawatan karena keterbatasan dana." (R1,R2)

Setiap peserta JKN berhak memperoleh manfaat jaminan kesehatan yang bersifat pelayanan kesehatan perorangan, mencakup pelayanan promotif, preventif, kuratif, dan rehabilitatif termasuk pelayanan obat dan bahan medis habis pakai sesuai dengan kebutuhan medis yang diperlukan. ${ }^{11}$ Berdasarkan ketentuan tersebut maka dibutuhkan ketersediaan bangunan yang memadai sehingga mampu menunjang segala keperluan dalam upaya mengoptimalkan pelayanan kesehatan kepada masyarakat. Menurut hasil wawancara dan observasi gedung yang dimiliki oleh puskesmas Tampaksiring I belum memenehui dan masih ada beberapa aspek yang perlu dibenahi lagi untuk mengoptimalkan pelayanan seperti penggunaan ruangan yang tidak sesuai. Hal ini mungkin bisa diperbaiki dengan cara memindahkan kegiatan imunisasi ke poli KIA karena berdasarkan observasi peneliti selama di puskesmas, peneliti merasa ruangan poli KIA jarang digunakan dan ruangannya cukup luas, disamping itu kegiatan imunisasi merupakan salah satu kegiatan dari program KIA jadi akan lebih baik menggunakan ruangan poli KIA dibandingkan menggunakan ruang istirahat pegawai.

Disamping masalah penggunaan ruangan yang tidak sesuai, permasalahan gedung puskesmas ini adalah masih terdapatnya ruangan yang tidak memiliki pencahayaan yang baik. Hal ini mungkin dapat disiasati dengan pemberian lampu yang cukup terang atau pun membuka korden jendela. Selain itu terdapat permasalahan gedung di puskesmas pembantu. Permasalah berupa tidak terawatnya gedung dengan baik. Hal ini dikarenakan gedung puskesmas pembantu tidak dimanfaatkan secara maksimal dan keterbatasan dana. Permasalahan ini dapat diatasi dengan pemanfaatan puskesmas pembantu secara maksimal dan pengecekan secara berkala oleh penanggung jawab terkait. Berkaitan dengan masalah perbaikan gedung mungkin bisa mulai dibuat rancangan anggarannya mengingat adanya peningkatan pendapatan puskesmas setelah berjalannya program JKN.

Permasalahan yang ada pada puskesmas ini tidak hanya terkait masalah gedung namun, infrastruktur nongedung puskesmas masih kurang memadahi. Hal ini dikarenakan syarat yang harus dimiliki oleh puskesmas sebagai PPK 1 adalah surat ijin gedung, alur pelayanan klinik dan administrasi, alat transportasi, peralatan laboraturium, obat-obatan medis dan emergency, peralatan medis, dan penanganan limbah puskesmas namun syarat tersebut masih ada yang belum terpenuhi. ${ }^{2,4}$ Berdasarkan observasi yang dilakukan, Puskesmas Tampaksiring I sudah memiliki surat ijin, alur pelayanan medis, kebutuhan administrasi yang memadahi, memiliki 2 buah mobil ambulans, 1 buah mobil puskesmas keliling, tempat sampah medis/nonmedis, peralatan medis gawat darurat, bahan habis pakai, dan alat sterilisasi. Hal ini didukung oleh informasi yang diperoleh dari informan sebagai berikut, 
“...peralatan yang tersedia di puskesmas ini sudah lengkap.sistem administrasi dan pengelolaan data di puskesmas ini sudah baik, hanaya saja sering kesulitan menginput data pasien karena server BPJS pusat yang sering sibuk hal ini membuat pekerjaan menjadi lama" (R3)

Namun terdapat kekurangan pada ketersediaan obatobatan gawat darurat, Obat-obatan tersebut tidak dapat ditemukan pada unit gawat darurat puskesmas. Saat dikonfirmasi hal tersebut kepada informan yang bertugas, mereka tidak dapat menunjukan tempat penyimpanan obat-obatan gawat darurat tersebut. Sedangkan untuk memenuhi persyaratan 144 penyakit yang harus dapat ditangani di Puskesmas, masih terdapat kendala dalam ketersediaan obat-obatan. Hal tersebut diperkuat oleh pernyataan informan sebagai berikut,

"...bantuan obat yang diberikan oleh dinas tidak lengkap sehingga ada beberapa obat yang tidak tersedia di puskesmas. Sebenarnya hal ini cukup menggangu dalam pelayanan, namun karena kami puskesmas BLU jadi sedang berusaha memebeli sendiri obat-obatan untuk melengkapi persediaan obat kami" (R1)

Selain itu masih terdapat kendala pada ketersediaan alatalat laboratorium. PPK1 seharusnya memiliki peralatan laboratorium sederhana seperti pengecekan gula darah, kadar kolesterol, pemeriksaan darah lengkap, urine lengkap dan juga pemeriksaan feses lengkap. ${ }^{2,4}$ Namun puskesmas hanya baru memiliki alat pengecekan gula darah dan kadar kolesterol, sedangkan untuk pemeriksaan darah lengkap baru akan dimasukan ke perencanaan anggaran tahun depan. Hal ini didukung oleh informasi yang diperoleh dari informan sebagai berikut,

"Peralatan lab masih kurang lengkap, tapi kita sudah rencanakan untuk anggarkan. Rencananya tahun depan kami akan memebeli alat untuk memeriksa darah lengkap. Hal ini menyebabkan kesulitan dalam penegakan diagnosis penyakit" (R1, R2, R3)

Berdasarkan hasil observasi dan wawancara, didapatkan puskesmas masih kurang dalam hal infrastruktur nonGedung. Obat-obatan gawat darurat ini sebaiknya selalu diperiksa ketersediaan serta tanggal kadaluarsanya secara berkala. Obat-obatan ini juga sebaiknya diletakkan pada lokasi yang mudah diraih dan mudah dilihat. Selain itu terdapat juga kendala dengan ketersediaan obatobatan tertentu untuk penanganan 144 penyakit yang harus dapat ditangani di puskesmas. Untuk masalah ini sebaiknya puskesmas lebih menghemat dana operasional pelayanan kesehatan agar dapat menganggarkan pembelian obat yang belum tersedia di Puskesmas
Tampaksiring I tersebut. Kendala lain yang dihadapi adalah belum lengkapnya peralatan laboratorium yang tersedia. Untuk menangani masalah ini Puskesmas Tampaksiring I sudah menganggarkan pembelian peralatan laboratorium. Namun mengingat syarat yang diberikan seharusnya pihak puskesmas lebih aktif dalam menghadapi permasalahan ini seperti peninjauan kembali pengaturan anggaran yang dilakukan setiap tahunya menjadi setiap 6 bulan sekali. Sehingga ketersediaan obat, bahan habis pakai dan juga peralatan laboratorium bisa segera lengkap.

Dengan hadirnya era JKN ini diharapkan di kemudian hari Puskesmas Tampaksiring I dapat mengembangkan infrastruktur gedung maupun non-Gedung yang belum tersedia. Jika misalnya peserta JKN di Puskesmas Tampaksiring I kurang lebih 12.000 dengan besar kapitasi Rp 6.000,- maka dana yang diterima puskesmas sebesar 72 juta rupiah per bulan atau 864 juta rupiah per tahun. $60 \%$ dari dana tersebut atau sekitar 518 juta rupiah akan menjadi dana operasional puskesmas. Di era JKN ini jika puskesmas berhasil melakukan promosi kesehatan serta pencegahan penyakit pada komunitas dan menekan jumlah kunjungan pasien, maka puskesmas dapat memaksimalkan dan menyimpan dana operasional tersebut. Dengan adanya peningkatan jumlah dana operasional ini diharapkan nantinya dapat memberikan kesempatan puskesmas untuk menganggarakan perbaikan dan pembelanjaan infrastruktur yang dapat menunjang pelayanan kesehatan.

\section{SIMPULAN}

Puskesmas Tampaksiring I masih memiliki kekurangan dalam faktor infrastruktur yang menonjol dalam pelaksanaan JKN baik dari gedung maupun non gedung. Permasalahan yang ada menuntut pihak puskesmas untuk lebih proaktif dalam meningkatkan kuantitas dan kualitas infrastruktur sehingga mutu pelayanan kesehatan pun dapat ikut ditingkatkan dan memenuhi syarat untuk menjadi PPK1.

\section{PERNYATAAN TERIMA KASIH}

Penulis mengucapkan ucapan terimakasih kepada Kepala Puskesmas Tampaksiring I beserta seluruh staf atas izin dan bantuan dalam rangka pengumpulan data.

\section{DAFTAR PUSTAKA}

1. Aspek-Aspek Hukum Asuransi dan Surat Berharga. Bandung: Alumni; 2003.

2. Checklist Standar Klinik Pratama PKFI tahun 2013. 
3. Kementerian Kesehatan Republik Indonesia. 2012. Peta Jalan Menuju Jaminan Kesehatan Nasional 2012-2019. Kemenkes RI. Jakarta.

4. Kementerian Kesehatan Republik Indonesia. 2013. Jaminan Kesehatan untuk Semua. Puskom Kemenkes RI. Jakarta.

5. Kementrian Kesehatan RI. KepMenKes Nomor 128/MENKES/SK/II/2004 Tentang Kebijakan Dasar Pusat Kesehatan Masyarakat. Man Suparman Sastrawidjaja

6. peran puskesmas di dalam masa jkn (bpjs) dan peran puskesmas dengan dokter keluarga pada masa bpjs ke depan

7. peraturan menteri kesehatan republik indonesia nomor 71 tahun 2013 tentang pelayanan kesehatan pada jaminan kesehatan nasional dengan rahmat tuhan yang maha esa menteri kesehatan republik indonesia,

8. Peraturan Presiden Nomor 12 Tahun 2013 Tentang Jaminan Kesehatan.

9. Puskesmas Tampaksiring I. 2013. Profil Puskesmas Tampaksiring I. Gianyar.

10. Undang-Undang Republik Indonesia No 40 Tahun 2004 Sistem Jaminan Sosial Nasional. 29 Oktober 2004. Lembaran Negara Republik Indonesia Tahun 2004 Nomor 4456. Jakarta.

11. Undang Undang Nomor 17 Tahun 2007 Tentang Rencana Pembangunan Jangka Panjang Nasional (RPJPN). Undang-undang Nomor 40 Tahun 2004 Tentang Sistem Jaminan Sosial Nasional. Williams \& Heins. Risk Management and Insurance, sixth ed. Singapore: McGraw-Hill Inc.;1989 